\title{
SIGNIFICADOS DAS PRÁTICAS DE NÃO CUIDADOS NA VISÃO DOS CLIENTES HOSPITALARES
}

\author{
Maria Itayra Coelho de Souza Padilha* \\ Ana Rosete Maia** \\ Mariana Vieira*** \\ Caroline Machado***
}

\section{Resumo}

Tem por objetivo identificar a percepção das formas de não-cuidado/violência, que ocorrem nas unidades hospitalares. A metodologia é qualitativa. Realizamos entrevistas com 29 clientes. Estabelecemos quatro categorias principais: desatenção, desrespeito, desconforto, irresponsabilidade. Os resultados indicam que o não cuidado/violência, é um Problema de Poder, relacionado ao desrespeito, preconceito e/ou discriminação pela condição social, sexual do indivíduo. Caracteriza-se por grosserias, má educação, prepotência, assédio sexual, desprezo, e indiferença dos profissionais da saúde. O não cuidado/ violência, como um Problema Assimétrico, expressa-se por atitude comportamental do poder e falta de uma comunicação dialógica horizontal. Relatam falta de atenção, interesse, vontade, e desconforto. Concluímos que as práticas de não cuidado/violência acontecem no cotidiano das inter-relações do processo de cuidar entre cliente e profissionais da saúde.

Descritores: enfermagem; cuidado de enfermagem; violência

\begin{abstract}
Its aim is to identify awareness of the types of non-care (lack of care)/violence that occur at hospital units. The methodology is qualitative and we have interviewed 29 clients. We have established four main categories: lack of attention, disrespect, discomfort, and irresponsibility. The results indicate that the lack of care/violence is a Power Problem related to disrespect, prejudice and/or discrimination due to a person's social/sexual condition. It is characterized by rudeness, impoliteness, arrogance, sexual harassment, contempt, and indifference on the part of healthcare professionals. The lack of care/ violence, as an Asymmetric Problem, is characterized by a behavioral attitude of power and by the lack of a horizontal dialogic communication. Lack of attention, interest and will, and discomfort have been reported. We concluded that the lack of care/violence practices occur in the everyday of the interrelations of the care-taking process between client and health professionals.

Descriptors: nursing; nursing care; violence Title: Meanings of non-care practices from the point of view of hospital clients
\end{abstract}

\section{Resumen}

Objetiva identificar la percepción de los estilos del no-cuidado/violencia, que acontecen en el proceso de cuidar en los servicios hospitalarios. La investigación es de naturaleza cualitativa. Los datos fueron colectados a través de la entrevista a 29 clientes. Establecemos cuatro categorías: descortesía, falta de respeto, falta de comodidad e irresponsabilidad. Los resultados indican el no cuidado/violencia, como un Problema del Abuso de Poder, relacionado a

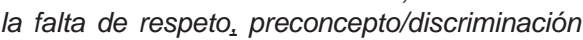
por la condición social y sexual del individuo. Caracterizándose estas por las groserías, la falta de educación, la prepotencia, el asedio sexual, el desprecio y la indiferencia de los profesionales de la salud. Como un Problema Asimétrico se expresaron mediante la actitud comportamental del abuso del poder y de la falta de una comunicación dialógica-horizontal. Se concluye que las prácticas del no cuidado/ violencia acontecen durante el día a día de las relaciones e interrelaciones del proceso de cuidar entre los clientes y los profesionales de la salud y las autoridades.

Descriptores: enfermería; cuidado de enfermería; violencia

Título: Significados de las prácticas de no cuidados según la visión de los clientes hospitalizados

\section{Introdução}

As demandas sociais têm chamado, internacionalmente, para uma crescente desumanização no Sistema de Saúde. Os avanços tecnológicos tendem a progredir. Os problemas de saúde têm desafiado a Ciências e os profissionais de saúde têm se defrontado com questões cada vez mais delicadas em relação a valores morais e éticos. Recentemente em países industrializados, a grande preocupação tem sido o resgate do sentido humanitário. O cuidado passa a receber prioridade englobando uma abordagem humanística, crítica e metafísica.

Um dos problemas encontrados, refere-se à desumanização nos serviços de prestação à saúde e à resultante despersonalização dos clientes $^{(1)}$. A consideração à pessoa como um todo e a consideração e sensibilidade à integridade do self, é basicamente, por assim dizer, uma ordem ética(1). O cuidar, como um valor profissional e pessoal, é de principal importância em prover padrões normativos os quais governam as ações e as atitudes em relação àqueles a quem se cuida. Nessa condição, os clientes estão à mercê de estranhos cujas funções e papéis desconhecem, de máquinas, aparelhos, testes assustadores e de rotinas totalmente desconectadas de seus conhecidos hábitos familiares. O cliente torna-se somente um objeto a mais, outra patologia, outro tratamento, outro prontuário, outro nome na lista do cronograma das salas de cirurgias, unidades e cardápios.

Os maiores desafios lançados à política orientada pela ética e ao modo-de-ser-cuidado são indubitavelmente os milhões de pobres, oprimidos e excluídos de nossas sociedades ${ }^{(2)}$. Esse antifenômeno resulta de formas injustas da organização social hoje mundialmente integrada. Com efeito, nas últimas décadas, verificou-se um crescimento na produção de serviços e bem materiais, entretanto, desumanamente distribuídos.

$\mathrm{Na}$ crise do projeto humano, sentimos a falta clamorosa de cuidado em toda a parte ${ }^{(2)}$. Suas ressonâncias negativas, são demonstradas pela má qualidade de vida, pela penalização da maioria empobrecida da humanidade, pela degradação ecológica e pela exacerbação da violência. Não busquemos o caminho da cura fora do ser humano, entendido em sua plenitude que inclui o infinito. Ele precisa voltar-se sobre si mesmo e redescobrir sua essência que se encontra no cuidado.

A realização de estudos relativos a investigar as práticas de cuidado e não cuidado são fundamentais, tendo em vista a complexidade e inter-relação dos problemas sociais, econômicos e políticos, resultantes das transformações no mundo, os quais afetam diretamente o serviço de saúde e interferem nas práticas de cuidado de profissionais de saúde. O cuidado à saúde é uma necessidade universal e vital para o processo de viver em sociedade. Contudo, a estrutura dos serviços e as práticas de cuidado à saúde parecem não responder adequadamente às necessidades da sociedade, exigindo iniciativas que possam através da criação e implementação de políticas inovadoras e criativas.

\footnotetext{
* Enfermeira. Professor Adjunto do Depto de Enfermagem da UFSC. Doutora em Enfermagem pela EEAN/UFRJ. Vice-lider do Grupo de Estudos da História do Conhecimento de Enfermagem (GEHCE). Pesquisadora do CNPq. **Enfermeira. Professor Assistente do Depto de Enfermagem da UFSC. Membro do (GEHCE). ${ }^{* *}$ Aluna do Curso de Graduação em Enfermagem da UFSC. Bolsistas de Iniciação Científica do CNPq. Membro do (GEHCE). E-mail do autor: padilha@nfr.ufsc.br
} 
Consideramos que as forças presentes nas práticas de cuidado à saúde são muitas e variadas, podendo ser concebidas tanto em complexidade como em intensidade, merecendo uma curada avaliação. Esta avaliação é necessária para que possamos tomar consciência dos problemas e da necessidade de mudanças, as quais possam assegurar uma maior acessibilidade às práticas de cuidado de custo efetivo e de qualidade.

Constatamos, na revisão da literatura, a existência de inúmeras pesquisas/estudos relatados de experiências relacionadas ao significado do cuidado em diferentes grupos, bem como percepções de cuidado do ponto de vista dos cuidadores e dos recebedores do cuidado. Cuidar em Enfermagem, consiste em esforços transpessoais de ser humano para ser humano, visando proteger, promover e preservar a humanidade, ajudando pessoas a encontrar significados na doença, sofrimento e dor, bem como, na existência. É ainda, ajudar outra pessoa a obter autoconhecimento, controle e autocura, quando então, um sentido de harmonia interna é restaurada(3). Entendemos cuidado como ações profissionais de natureza disciplinar e interdisciplinar, que se dão no processo de interação terapêutica entre seres humanos, fundamentadas em conhecimento empírico, pessoal, ético, estético e político, com a intenção de promover a saúde e a dignidade no processo de vida humana ${ }^{(4)}$

Em estudo realizado para investigar as atitudes de cuidados do ponto de vista dos profissionais de saúde a clientes portadores de Aids, foram detectados que o convívio com o diagnóstico, pelo cliente, continua trazendo grande impacto, tanto para si quanto para os familiares. O que determina a aceitação da doença, não parece ser o tempo, mas o juízo de valores que se atribui ao fato. O convívio com a doença parece provocar muitos sentimentos: a compaixão, o apego, satisfação, sofrimento, a dor pela estigmatização. Permeando esta rede de sentimentos, está a relação de cuidado, que é o ponto de encontro entre o cliente e o profissional. E para a realização do cuidado, estão as atividades expressivas, instrumentais, a educação, a disponibilidade, o relacionamento interpessoal(5).

Por outro lado encontramos poucos estudos que refletem o não cuidado na percepção dos recebedores do cuidado. O nosso entendimento das ações de não cuidado/ violência em saúde consistem de atos caracterizados sob quatro vertentes: a) como um Problema de Poder: quando a violência física, psicológica ou moral é praticada direta ou indiretamente por uma pessoa ou grupo de pessoas, contra outra pessoa ou grupo de pessoas ou coisas. A violência é apenas o instrumento ou a expressão do poder, e este é o cerne da questão; b) como um Problema assimétrico: o desequilíbrio entre entidades heterogêneas é essencial como pré-condição para a violência. Quanto maior a desigualdade maior o potencial de violência; c) como Anti-Ação: a força exibida como violência é uma força destrutiva, mata, mutila, fere, desfigura o corpo e altera as funções orgânicas. Produz, ainda desequilíbrio emocional, medo, deformação e destruição, tanto de estruturas individuais quanto coletivas; d) como Pró-Ação: esta forma particular de poder exercida através da força, não é somente almejada pra destruir ou negar uma ordem ou sistema legal; pode também ser exercida para afirmar ou defender um direito ou construir uma ordem ou sistema legal(6).

Este estudo tem por objetivo analisar as formas de não cuidado desenvolvidas em unidades hospitalares, do ponto de vista de quem recebe o cuidado e refletem sobre o processo de interação existente entre estes e os profissionais de saúde.

\section{Metodologia}

Realizamos este estudo qualitativo, do tipo exploratório descritivo, a fim de identificar formas de não cuidado/violência que possam ocorrer no processo de interação entre profissionais de saúde e clientes, em serviços hospitalares da
Grande Florianópolis, como parte do projeto financiado pelo Ministério da Ciência e Tecnologia - MCT e pelo Conselho Nacional de Desenvolvimento Científico e Tecnológico - CNPq, através do Plano Sul de Pesquisa e Pós-Graduação intitulado: Avaliação das Práticas de Cuidado de Profissionais de Saúde em Serviços Hospitalares do Estado de Santa Catarina.

Os dados foram coletados através de um instrumento, com entrevistas semi-estruturadas a um grupo de 89 clientes, sendo que a amostra foi de 29 indivíduos adultos, assistidos em três hospitais públicos de grande porte, da região da grande Florianópolis, os quais consentiram em participar do estudo e preencher os critérios de seleção propostos para a pesquisa. Tais critérios foram: os clientes estarem orientados no tempo e no espaço; aptos para apresentarem informações; que não estivessem sob uso de medicamento narcótico ou similar; que não manifestasse qualquer desconforto físico e/ou emocional que dificultasse sua participação; bem como, que assinassem o termo de consentimento.

Os dados foram analisados do seguinte $\operatorname{modo}^{(7,8)}$ a) duas pessoas procederam a leitura linha a linha, parágrafo à parágrafo, para a extração das palavras e frases indicativas dos significados e as agruparam designando-as com nomes que englobassem os indicadores semelhantes; b) duas outras pessoas revisaram e sugeriram modificações; c) uma terceira pessoa revisou e validou o sistema final de categorização que foi então processado em computador.

Foram perguntadas aos clientes questões sobre o não cuidado, tais como: O que significa para o senhor(a) não cuidado? Nas respostas dos 29 indivíduos relacionados a tal pergunta, a qual objetivou captar significados e percepções do cliente em relação ao cuidador (profissional da saúde), sobre atitudes e comportamentos de não cuidado. Emergiram os seguintes temas: falta de atenção, interesse e vontade; desprezo e falta de respeito pelos profissionais; condições do ambiente impróprias com falta de infra-estrutura, conforto e comodidade. Em relação a pergunta: Você já se sentiu alguma vez atitudes de discriminação/preconceito, violência nesta instituição hospitalar? Os temas que emergiram, nas respostas dos clientes entrevistados foram: discriminação preconceito pela condição social do cliente.

\section{Atitudes de não cuidado manifestas no discurso}

Percebe-se que o tema, falta de atenção, interesse e vontade foi o mais citado entre os respondentes, os quais obtiveram expressões como: atendimento sem solicitude, presteza e sem afetividade; incompetência técnica, de assepsia/ controle de infecção; falta de sensibilidade, de solidariedade e de compaixão.

Quando não dão importância para aquilo que sentimos ou não escutam, não conversam [...] já estamos fragilizados, então qualquer mau tratamento ou desatenção é motivo de piora (C 15.15).

A demonstração de afeição é um elemento relevante nas relações de cuidado, segundo as pessoas entrevistadas. Alguns autores de enfermagem ${ }^{(9)}$ definem cuidado como uma afeição, enfatizando que a natureza do cuidado advém do envolvimento emocional do enfermeiro com o cliente, ou um sentimento de empatia pela experiência do mesmo.

O cuidado está associado geralmente ao termo atenção, preocupação, responsabilidade, afeto, amor ou simpatia, e ainda, ação ${ }^{(10)}$.

O cuidar está relacionado a uma responsabilidade em responder a uma necessidade ${ }^{(11-13)}$ como um fenômeno moral, que aponta para os atributos mais usuais, contidos no conceito, tais como o cuidar como um modo de ser, como uma pré-condição para ser iniciado o processo, como um ideal moral e social.

Devemos estar alerta ${ }^{(14)}$ para o componente cognitivo desse aspecto moral, representado pela percepção da necessidade e do dever em satisfazer a necessidade. 
Outros autores ${ }^{(15,16)}$ têm salientado esta questão de dever ou de obrigação no cuidar e têm causado algumas reações. O cuidado exige do profissional de saúde conhecimento, ritmos alternados, paciência, honestidade, confiança, humildade, esperança e coragem ${ }^{(16)}$.

O cuidar é mais que um ato; é uma atitude(2). Portanto, abrange mais que um momento de atenção, de zelo, e de desvelo. Representa uma atitude de ocupação, preocupação, de responsabilização e de envolvimento afetivo com o outro.

Nas respostas do cliente relacionadas ao tema desprezo e falta de respeito, expressam-se como: atitudes grosseiras, não éticas em relação à situação saúde/doença do cliente; falta de confiança, de compreensão; a não permanência do acompanhante no quarto; falta de educação, prepotência, arrogância dos profissionais de saúde. O que foi exposto pode ser exemplificado:

[...] alguns profissionais acham que são fingimento nossas queixas, penso que não devem duvidar [...]. Quem trabalha na saúde deve saber lidar com os doentes, ter vocação, requisitos de boa personalidade (C 13.13)

O ideal moral e ético dos profissionais de saúde que cuidam devem expressar características humanitárias, afetivas, relacionais, vocacionais e uma ética voltada para a justiça e respeito aos direitos, visando tornar o ser-cuidado, em condição plena de cidadania.

Os sentimentos negativos em relação à interação com o cuidador, expressos pelos clientes, quanto aos cuidados, eram de que estes, sentiam-se diminuídos, excluídos como pessoas.

A impaciência e o desinteresse demonstrado nos comportamentos dos cuidadores geram sentimentos de vergonha, medo e raiva; os quais, sentem-se insignificantes de estarem aborrecendo os cuidadores ${ }^{(17)}$.

$\mathrm{Na}$ compreensão do cliente em um ambiente hospitalar, percebe-se a importância da presença do cuidador seja ele, profissional da área da saúde, pais, familiares, companheiros de quarto, visitas ou pessoal do hospital. A presença das pessoas interagindo com o cliente, permite-lhe elaborar com mais facilidade seus sentimentos e emoções, controlar sua ansiedade, temores, medo e fantasias organizando melhor seu mundo anterior. Pois, para o cliente hospitalizado, a presença do acompanhante é fonte de proteção e segurança.

A necessidade de proteção, livre do perigo e seguro, que o ser humano apresenta, surge logo após as necessidades fisiológicas ou básicas serem saciadas; tais como, alimentação, sede, sono, abrigo. Entretanto, para que as necessidade fisiológicas sejam satisfeitas, faz-se necessário que primeiro sejam saciadas as necessidades de proteção e de segurança(18).

A impossibilidade da permanência do acompanhante junto ao cliente, se deve na maioria das vezes a lógica da instituição que é normativa, burocratizante e centralizadora, pouco sensível à preocupação e angustia da família/ acompanhante, no enfrentamento de um corpo biológico, doente, com dimensão emocional, subjetiva e de relações sociais, que tenta manter a normalidade da vida, mesmo com os limites impostos pela hospitalização. Para o acompanhante/ família a hospitalização é um momento crítico e delicado em sua vida familiar e social. Pois, implica mudanças do ambiente físico e psicológico, separação, enfraquecimento de vínculos, interrupção das atividades cotidianas, entre outras.

A fim de atender estas necessidades das famílias, as instituições e equipes precisam alterar-se, buscar referenciais sociais e psicológicos, subsídios para reorganização da assistência e do cuidado.

Ao estudar as relações de poder, levantou-se a idéia de que a disciplina e o controle são inerente aos profissionais de saúde, ora como sujeição aos superiores, ora como exercentes do poder junto aos demais membros da equipe de enfermagem e aos clientes. Esta negação de si mesmo, na atitude dos suposto comando, frente ao acordo estabelecido no contrato da relação, permite a suportabilidade da submissão, ausência de rebeldia e crítica do cotidiano, impossibilitando que a própria organização institucional busque alternativas e mecanismos de intervenção e comunicação objetivando, o acolhimento e uma melhor qualidade da ação profissional no cuidado aos clientes ${ }^{(19)}$.

Em relação ao tema, segurança/proteção expressados nas respostas dos clientes pesquisados, este é ao mesmo tempo um sentimento e uma necessidade que as pessoas tem em relação a sua vida, estando aí no mundo. Este sentimento foi expresso como: ter disponibilidade de tratamento para cura, controle da doença e alívio de sintomas, ter trabalho, ter recursos para custear o tratamento, sentir-se protegida com as pessoas ao seu redor, sentir segura por ter acertado o tratamento, sentir que tem condições de sobreviver.

Quando o paciente percebe sua situação ser indiferente ao profissional do cuidado, sente-se não cuidado e pode, sentirse ameaçado, vulnerável(20).

No tema condições do ambiente impróprias com falta de infra-estrutura, conforto e comodidade, as respostas por parte dos clientes expressaram como: equipamentos hospitalares poucos ergonométricos, com sujidade e tecnologia ultrapassada; espaço físico com dimensões reduzidas e pouco ventilado; conservação e limpeza da unidade do cliente deficiente; unidade de internação mista, com perdas da privacidade/intimidade; falta de materiais de consumo e insumos para a realização de procedimentos; número de funcionários inadequados para prestar um cuidado seguro e de qualidade; como também oferta nutricional pouco adequada ao gosto dos clientes. Este tema, pode ser exemplificado:

A limpeza não tá boa, nos outros quartos a cortina tá no chão. Faltam pessoas que saibam administrar melhor e com mais responsabilidade [...] também faltam recursos para manter a estrutura adequada, como gaze para realizar os curativos, produtos de limpezas [...] às vezes vejo que é só com água (C 11.11).

Uma questão que deve ser considerada é o meio ambiente. Por vezes fica difícil, senão impossível, favorecer o cuidado, se o ambiente é hostil, se a equipe não valoriza o cuidado, tratando os clientes como objetos e se a instituição como um todo não oferece apoio para que o cuidado ocorra. O cuidado como contexto de humanização do ser profissional/ cliente refere-se ao local onde desenvolve-se o cuidado e a relação profissional/cliente/familiar, onde todas as interrelações e relações possibilitam aos seres crescerem e tornarem-se mais humanos, mais solidários, sensíveis e conectados a natureza, ao cosmo, ao mundo.

Nesse sentido, os profissionais de saúde precisam fazer uso do poder do cuidado para garantir um ambiente propício, ou, em outras palavras, um ambiente de cuidado, envolvendo o meio físico, o administrativo e o social. Para que este meio ambiente de cuidado seja favorecido é necessário que cuidadoras entendam o significado de cuidar e o valorizem, sentindo-se motivadas, para que o cuidado seja uma prática dos profissionais da saúde e de todo o sistema.

O não cuidado em relação ao meio ambiente, é importante $^{(20)}$. E pode ser identificados como uma questão de poder, ou melhor, a falta de poder e o reconhecimento do cuidado, a sua desvalorização, a negligência, a falta de responsabilidade, entre outros. Nas respostas dos clientes, percebe-se que o tema conforto/desconforto aparece como um componente importante no cuidado e não cuidado.

O cuidado como conforto significa estar presente em sua totalidade, junto à pessoa que cuidamos, é presença intencional e expressão única na relação entre cuidador e seu cuidado. É o cuidado real, autêntico.

Encontramos em algumas teorias de enfermagem referências ao termo conforto. Estas definem enfermagem como 
um processo interpessoal nutridor e confortador e consideram em uma de suas pressuposições que o cuidado de enfermagem inclui ambos, conforto (care) e desconforto (cure). Além disso, identifica três conceitos centrais de sua teoria, care, core, cure os quais focalizam respectivamente o corpo, a pessoa e a doença. O conforto é visto como um dos componentes do cuidado íntimo do corpo, juntamente com alimentação, banho posicionamento(21). O desconforto é impingido pela enfermeira quando realiza procedimentos para a cura da doença, como: administração de medicamentos e tratamento(24).

A manutenção de boa higiene e conforto físico é colocada como um dos vinte e um problemas de enfermagem ${ }^{(23)}$. Para que as necessidades dos pacientes sejam satisfeitas é preciso que as enfermeiras lhes assegurem conforto físico e mental(22). Por estas colocações, pode-se depreender que as teoristas de enfermagem enfatizam a faceta do conforto físico e mental enquanto necessidade humana básica.

Conforto é uma variável que afeta o ambiente externo e interno das pessoas e sugere, como um dos fatores de cuidado de sua teoria, a provisão de um ambiente de cuidado que inclua os aspectos físico-mental-sociocultural e espiritual(25).

A enfermagem humanística é vista como diálogo autêntico envolvendo encontro, relacionamento e presença no mundo das pessoas no tempo e espaço. Este encontro autêntico resulta em conforto porque a pessoa pode estar confortável mesmo quando não se está saudável. E a preocupação central da enfermagem é a promoção de uma maneira confortável de ser, não apenas a preocupação com o bem estar, mas com o "ser mais" das pessoas. Portanto, o conforto traz consigo a noção de que o ser humano é "tudo aquilo que ele pode ser de acordo com o seu potencial em determinado tempo e em determinada situação" (26:101)

As idéias de Paterson ${ }^{(26)}$ a respeito do constructo conforto focalizam tanto o que ocorre nas relações enfermeira-pessoa como o que resulta deste encontro (o conforto). Sendo que a experiência de conforto do cliente percebida pela enfermeira deve ser validada por ele enquanto cliente. Esta experiência é individual, única e temporal, pois varia de pessoa para pessoa e para cada pessoa em diferentes momentos.

O ambiente confortável/adequado parece significar algo além de simples comodidade. O hospital torna-se um ambiente confortável, quando os componentes da equipe de saúde o tornam assim. A delicadeza no tratar o cliente, atendendo com solicitude, bondade e respeito são fundamentais para que este, sinta-se confortável, mesmo estando imobilizado num leito de hospital.

Destaca a influência do meio ambiente na vida e na saúde do ser humano, e enfatiza a importância de boas condições de ventilação (ar fresco), calor, luz solar, dieta, higiene e sanitarismo que facilitam ao cliente ativar seu poder de autocura $^{(27)}$. Depreende-se, desta forma, a necessidade premente de ser o hospital, um lugar com bastante silêncio, bem arejado, com janelas grandes que permitam a entrada de luz solar, ar fresco e puro, como também, que forneça dieta equilibrada e haja bastante higiene, suficiente para que o ser cuidado não saia pior do que entrou no hospital. O ambiente hospitalar deve ser ainda um lugar alegre, cheio de vida e nunca um lugar hostil, cinzento, despido de cor, pois o ambiente tem um papel importantíssimo no sentido de dar alternativas e estimulações. Este ambiente adequado, juntamente com as ações de cuidado emocional-afetivo e técnico científico do cuidador holístico estimulam o sentimento de melhora do ser cuidado, colaborando para que sua recuperação se efetue mais rápida e eficazmente.

Um dos fatores de cuidado é a provisão de um ambiente que fortaleça a imagem pessoal e auto-estima, através da atenção holísticas para os aspectos físicos, mentais, sóciosculturais e espirituais ${ }^{(25)}$. Este ambiente envolve comodidade, privacidade, segurança e aspectos estéticos e de higiene, ou seja, é um ambiente de cuidado que facilita o alcance do conforto por parte de quem cuida e de quem é cuidado.
Entende-se como comodidade, a sensação gerada pela obtenção de condições ambientais ou materiais favoráveis tais como ter casa para morar, comida, lugar para dormir, roupa limpa, deitar na sua própria cama, tomar banho de chuveiro quente. Inclui ainda, os procedimentos realizados no cuidado profissional, como posicionamento e alinhamento das partes do corpo, mudar a roupa de cama, realizar a higiene corporal, proporcionar ambiente adequado para o repouso e descanso, controle de temperatura, odores e ventilação do ambiente. A dimensão tempolespaço de internação é uma variável importante que permeia o estar confortável - desconfortável. Proporciona ao cliente avaliar sua situação e buscar significados nesta.

A dignidade do cliente, recebedor do cuidado, relacionase tanto com o ambiente físico, quanto o emocional e ocorre sob determinadas condições, dentre as quais está o afeto, calor humano, atenção, amor que propicia o crescimento, alívio, segurança, proteção, bem estar ou seja, um ambiente no qual a pessoa experencia o cuidado humano. Conforto é considerada como uma variável proveniente do ambiente externo e que por isto pode ser, em parte, controlada pela enfermeira. Ao incluir conforto como um de seus fatores de cuidado estava enfatizando a relação íntima que existe entre os conceitos cuidado e conforto(25).

Nas respostas da questão: "Você já se sentiu alguma vez atitudes de discriminação/preconceito, violência nesta instituição hospitalar?" Os clientes expressaram: discriminação preconceito pela condição social do cliente, como: não possibilitar ao cliente o direito de escolha e decisão em relação ao cuidado a ser prestado; a não valorização de sua queixas e opiniões críticas, através da hostilização; discriminação e preconceito em relação a cor, sexo, religião, e o tipo de orientação sexual do cliente; discriminação dos profissionais da saúde na realização de procedimentos, como biópsia, punção venosa, curativos, etc, principalmente quando o cliente apresenta os diagnóstico, como AIDS, tuberculose, etc; não informação correta sobre o procedimento a ser prestado; e ainda discriminação em relação a condição jurídica do cidadão (usuários de drogas ilícitas, presidiários). Este tema pode ser exemplificado, na frase do cliente: [...] Por ser portador da AIDS, já fui maltratado com grosserias, desprezo, no momento do curativo. (C 0.10).

Ao discutir os significados atribuídos à experiência da enfermidade(28) os indivíduos conferem significados e desenvolvem modos próprios de lidar com a situação e as respostas aos problemas criados pela doença se remetem diretamente a um mundo compartilhado de práticas, crenças e valores. O autor acrescenta que a vivência da enfermidade pelo indivíduo, assim como por aqueles que estão envolvidos (familiares, amigos, vizinhos, terapeutas) é reproduzida a partir do universo sociocultural do qual estas pessoas fazem parte.

Em estudo fenomenológico sobre o cuidado, no qual os clientes descreveram interações de cuidado e não cuidado foi observado que nas descrições dos clientes, as interações relatadas foram sempre primeiramente as de não cuidado, o que a pesquisadora atribuiu ao fato de os clientes estarem vivenciando, uma experiência nova e estranha. Eles reportaram também como conseqüentes interações de não cuidado, sentimentos de humilhação, medo e sensação de estar fora do controle de sua própria situação(29). Em outro estudo(30) foi observado que existem cinco modos básicos de estar com o outro, segundo os relatos de clientes: vida-destruição, onde um despersonaliza o outro, destrói a apreciação da vida e, aumenta a vulnerabilidade do outro; vida-repressão, modo em que um é insensível ou indiferente ao outro; vida-neutralização, quando um não afeta a vida do outro; vida-sustentação, quando se conhece a personalidade oculta do outro, no qual se encoraja e reafirma; vida-doação é o modo que há crescimento e potencialização do aprendizado da saúde. 


\section{Considerações Finais}

Consideramos que a experiência de saúde/doença exige que o cuidado vincule o direito ao conforto, propiciando aos seres cuidados integração, liberdade, melhora de sua condição, segurança e proteção, além de comodidade, dignidade e fortalecimento de sua cidadania, dentro dos princípios da justiça social. O estudo demonstrou que o cuidado e o não cuidado estão relacionados a respectivos contextos de apoio e não apoio. A ênfase na verdade é o relacionamento entre o contexto social e como os indivíduos, engajam-se em atos de cuidado(31).

Este estudo possibilitou o desvelamento da prática de não cuidado aos clientes assistidos nas instituições hospitalares pesquisadas demonstrando a necessidade de conhecermos como acontece estas práticas, no cotidiano do processo de cuidar dos profissionais de saúde, refletindo ações de não cuidado físico, psicológico, social, que muitas vezes estão relacionadas ao modelo econômico e social e político, pelo qual o país e a sociedade atravessam. Percebemos que há muito mais para se fazer no intuito de melhorar esta condição e pouco para se orgulhar dos serviços oferecidos nos hospitais. É aqui que entra a responsabilidade de todos os profissionais de saúde envolvidos.

Estes profissionais de saúde devem ter o cuidado como seu foco principal, fundamentado em suas raízes históricas, buscando resgatar e construir um novo marco para as práticas de cuidado alicerçado nos direitos humanos e na justiça social, desenvolvendo a cidadania de todos os indivíduos envolvidos no cuidado à saúde e os empoderando para que a conquista e a garantia de seus direitos à saúde e a vida seja um acontecimento real. Portanto, acreditamos que é tempo dos profissionais de saúde encontrarem seu espaço, sua própria identidade como cuidadores. É tempo destes profissionais compreenderem que são participantes ativos no processo de cuidar, através do diálogo horizontal e da conscientização, objetivarem provocar mudanças nas atitudes e práticas do cuidar em saúde, defendendo e argumentando em favor dessa causa, influenciando o poder e as políticas de saúde, em questões e problemas que concernem aos cidadãos ou seres cuidados, sobretudo àqueles marginalizados e excluídos, apoiando-os em suas lutas e decisões, com atitude e ação da experiência da compaixão e da solidariedade ativa e pró-ativa.

Este estudo indica que o cuidado e não cuidado/violência refletem questões e interrelações de poder. Já as práticas de não cuidado/violência são Problemas de Poder que relacionamse ao desrespeito, preconceito e/ou discriminação pela condição social, sexual do indivíduo. O não cuidado/violência pode ser visto como um Problema Assimétrico, expressandose por atitude comportamental do poder e falta de uma comunicação dialógica horizontal, entre o cliente e os profissionais da saúde, expresso como falta de atenção, interesse, vontade, bem como desconforto. Percebemos portanto, que as práticas de cuidado e não cuidado/violência acontecem no cotidiano das relações e inter-relações do processo de cuidar.

Consideramos que a análise preliminar deste estudo corrobora os estudos de vários autores, como também indica que cada vez mais necessitamos desenvolver estudos para compreendermos a realidade da prática do cuidar/cuidado como possibilidade para um cuidar/cuidado com qualidade ${ }^{(32)}$.

\section{Referências}

1. Carper BA. "The ethics of caring". Advances in nursing Science 1979 april; 1(3):11-9.

2. Boff L. Saber cuidar: Ética do Humano-Compaixão pela terra. Petrópolis(RJ): Vozes; 1999. 243p.

3. Waldow VR, Lopes MJM, Meyer DE. Maneiras de cuidar, maneiras de ensinar. Porto Alegre(RS): Artes Médicas; 1995. 265p.

4. Padilha MICS, Silva AL, Maia AR. Programa de pesquisas colaborativas de avaliação das práticas de cuidado de profissionais de saúde em serviços hospitalares de Florianópolis(SC). Projeto de Pesquisa vinculado ao Plano Sul de Pesquisa e Pós-Graduação em parceria do MCT/CNPq; 2003. 36p. (Projeto $n^{\circ}$ 52.0692/01-2).

5. Alves IC, Padilha MICS. A equipe de enfermagem e o exercício do cuidado a clientes portadores do vírus HIV/aids. Revista Enfermagem UERJ; 2004. (no prelo).

6. Camargo CL, Buralli KO. Violência contra crianças e adolescentes. Salvador( BA): Ultragraph;1998. 187p.

7. Strauss A. Qualitative analysis for social scientists. New York: Cambridge University Press; 1988. 420p.

8. Siedel J, Friese S, Leonard DC. The Ethnograph v 4.0: A program for the analysis of text based data. Amherst (MA): Qualis Research Associates; 1995.

9. Morse JM, Soberg SM, Neander W. Concepts of caring and caring a concept. Advances in Nursing Science 1990 Oct; 13(1):1-14.

10. Waldow VR. Cuidado: uma revisão teórica. Porto Alegre(RS)Revista Gaúcha de Enfermagem Porto Alegre(RS) 1992 jul; 2(13): 29-35.

11. Fry ST. The philosophical foundation of caring. In: Leininger MM, editor. Ethical and moral dimension of care. Detroit (MG): Wayne State University Press; 1990. 239p.

12. Gaut DA, Leininger MM. A theory of caring: pitfalls and promises. In: Gaut DA, Leininger MM, editors. Caring: the compassionate healer. New York: National League for Nursing;1991.275p.

13. Gaut DA. The ethic of care: nursing's excellence for a troubled World. In: Gaut DA, editors. A Global agenda for caring. New York: National League for Nursing Press;1993.275p.

14. Griffin AP.A philosophical analysis of caring in nursing. Journal of Advanced Nursing 1983 Aug;8:289-95.

15. Noddings N. Caring: a feminine approach to ethics and moral education. Berkeley(CA): University of California Press; 1984. 178p.

16. Reis AL, Xavier I. Mulher e AIDS: rompendo o silêncio da adesão. Revista Brasileira Enfermagem, Brasília (DF) 2003 jan/fev; 56(1):2834.

17. Drew N. Exclusion and confirmation: a phenomenology of patient's experiences with caregivers. Image Journal of Nursing Scholarship Indianápolis (ID) 1995 may; 18(2): 39-43.

18. Maslow A. Motivação e personalidade. São Paulo: Harper e Row;1979. $132 p$.

19. Padilha MICS. A mística do silêncio: a enfermagem na Santa Casa de Misericórdia do Rio de Janeiro no século XIX. Pelotas(RS): Ed. Universitária / UFPEL; 1998. 230p.

20. Waldow VR. Cuidado humano: o resgate necessário. Porto Alegre(RS): Sagra Luzzatto;1998. 265p.

21. Torres G. Theoretical foundations of nursing. Norwalk (CN): AppletonCentury-Crofts;1986. 348p.

22. Marriner-Tomey A. Nursing theorists and their work. St. Louis (MO): C.V. Mosby; 1994. 197p.

23. Abdellah HG, Beland IL, Martin A, Matheney RV. Patient Centered approaches to Nursing. New York: MacMillan; 1960. 273p.

24. Orlando IJ. The dynamic nurse-patient relationship: function, process, and principles. New York: GP Putnam's sons; 1961. 146p.

25. Watson J. Nursing: the philosophy and science of caring. Boston (MA): Little Brown; 1979. 272p.

26. Paterson JG., Zderad LT. Humanistic nursing. New York: National League for Nursing;1988. 236p.

27. Nightingale F. Notes on nursing: What it is and What it is not. New York: Dover; 1969. 165p.

28. Alves PC. Significação e metáforas na experiência da enfermidade. In: Rabelo MCM, Alves PCB, organizadores. Experiência da doença e narrativa. Rio de Janeiro: Fiocruz; 1999. 250p.

29. Riemen DJ. Non caring and caring in the clinical setting: patient's descriptions. Topics in Clinical Nursing 1986 jun; 8(2): 30-36.

30. Halldórsdóttir S. Five basic modes of being with another. In: Gaut DA, Leininger MM, editors. Caring: the compassionate healer. New York: National League for Nursing 1991; 150p.

31. Greenleaf NP. Caring and not caring: the question of context. In: Chinn PL, editors. Anthology on caring. New York: National League for Nursing Press; 1991.189p.

32. Maia ARC. Elementos e dimensões do cuidado na perspectiva de clientes ambulatoriais. Revista Texto \& Contexto Enfermagem, Florianópolis(SC) 1998 set/dez;7(2):133-50.

Data de Recebimento: 06/06/2004

Data de Aprovação: 22/12/2004 